\title{
Infogain attribute evaluator and ANN based wind speed prediction model for rajasthan, north-west region of India
}

\author{
Priya Garg ${ }^{1 *}$, Sachin Kumar Soy ${ }^{1 \#}$, A.P. Mittal ${ }^{1}$, H. Malik ${ }^{1}$ and Amit Kumar Yadav² \\ ${ }^{1}$ Division of Instrumentation and Control Engineering, NSIT, New Delhi, India \\ ${ }^{2}$ Department of Energy \& Environment, NIT Hamirpur, H.P., India \\ Email: * pgarg.nsit@gmail.com; sachinkumarsoy@gmail.com
}

The installation of wind turbine in a particular location in India is based on the wind speed prediction. The wind speed can be predicted using different models. The average temperature, maximum temperature, minimum temperature, ambient temperature, dew-point temperature, air pressure, vapor pressure, atmospheric pressure, solar radiation, altitude, longitude, wind direction, mean sea level, relative humidity, time of the day, water vapor, wind power are input variables to the Artificial Neural Network (ANN) which affects the accuracy of the wind speed prediction. Therefore, the selection of the most relevant input variables to the ANN model is necessary. With this main objective, InfoGain Attribute Evaluator with Ranker Search Method is applied to find the most relevant input variables. Identified relevant input variables are used as input for ANN Model to predict the wind speed. The results obtained validates that the combination of input variables selected through InfoGain Attribute Evaluator gives higher prediction accuracy than any other combination of input variables. This method is used to predict the wind speed in Rajasthan, north-west region of India.

The MATLLAB based graphical results are shown in Figure 1 to 3, which are used to further validation of the proposed model.
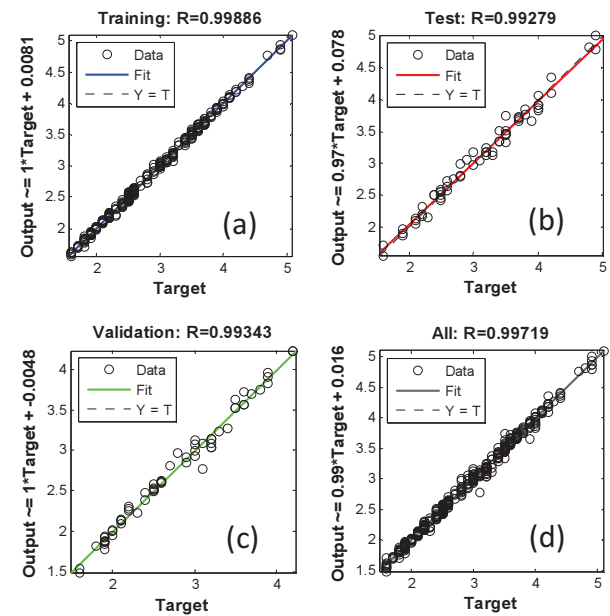

Figure 1: Regrasion plot of (a) training, (b) testing, (c) validation, (d) over all regresion of the model

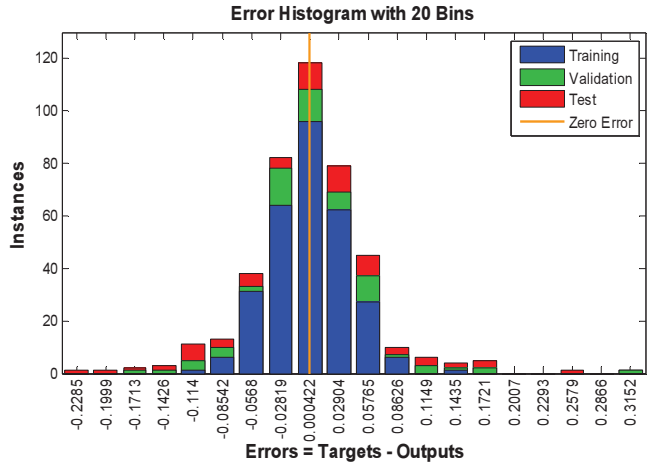

Figure 2: Error Histogram plot

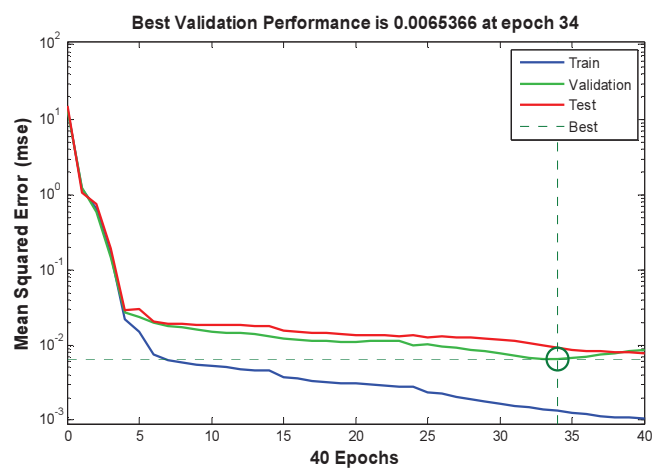

Figure 3: Performance plot

\section{References}

1. Amit kumar yadav, Hasmat Malik, S.S. Chandel, Renewable and Sustainable Energy Reviews, Vol. 31, (2014): 509-519.

2. Mark Hall, Eibe Frank, Geoffrey Holmes, Bernhard Pfahringer, Peter Reutemann, Ian H. Witten. The WEKA Data Mining Software: An Update; SIGKDD Explorations, Vol. 11, No. 1, 2009.

3. Hasmat Malik, Sukumar Mishra \& Alok Prakash Mittal, Electric Power Components and Systems, vol. 42, issue 16 (2014): 1849-1861.

4. MATLAB User's Guide. The MathWorks, Inc., Natick, MA 01760, 1994-2001. 